\title{
Current Status of Extracorporeal Membrane Oxygenation for Severe Respiratory Failure
}

\author{
Shingo Ichiba and Robert H. Bartlett \\ University of Michigan Medical Center, Ann Arbor, Michigan, U.S.A.
}

\begin{abstract}
Extracorporeal membrane oxygenation (ECMO) for respiratory failure was reviewed. ECMO progressed from laboratory research to initial clinical trials in 1972. Following a decade of clinical research, ECMO is now standard treatment for neonatal respiratory failure refractory to conventional pulmonary support techniques worldwide. The application of neonatal ECMO has been extended with improved outcome to premature and low birth weight infants as well as older children and adults.
\end{abstract}

As of July 1994, 9,258 neonates, 754 pediatric, and 130 adult patients with respiratory failure treated with ECMO were entered in the registry of the Extracorporeal Life Support Organization (ELSO). Overall survival rates were $81 \%$ in neonates, $49 \%$ in pediatric, and $38 \%$ in adult patients. Recently the adult and pediatric populations treated with ECMO have increased rapidly, and the outcome has improved significantly. Key Words: Extracorporeal membrane oxygenation-Respiratory failure.
Extracorporeal membrane oxygenation (ECMO) refers to the use of prolonged extracorporeal circulation for temporary support of the failing heart or lungs. The first successful ECMO support case was done by Hill et al. in 1971. Reports of several other successful cases soon followed. In 1974, the Lung Division of the National Heart and Lung Institute proposed a multicenter prospective randomized study of ECMO in adult respiratory failure. This study began in 1975 . In that year a meeting on prolonged extracorporeal support was held outside of Copenhagen. The plans for the NIH-ECMO study were reported and reviewed at that meeting. The first successful newborn infant with ECMO was also reported on at the meeting.

\section{NEONATAL ECMO}

Bartlett, Gazzaniga, and his colleagues at the University of California-Irvine treated the first successful neonatal ECMO patient in 1975. This was

Received September 1995.

Address correspondence and reprint requests to Dr. Shingo Ichiba at University of Michigan Medical Center, $1500 \mathrm{E}$. Medical Center Drive, 2918 Taubman Center, Box 0331, Ann Arbor, MI 48109, U.S.A. soon followed by other successful neonatal cases. The technique for newborn infants was fairly standardized including the ECMO technique and recognition of persistent pulmonary hypertension as the primary underlying pathophysiology. In 1979, the first neonatal ECMO seminar was held at the University of California-Irvine, demonstrating the circuit, technology, and concept of the ECMO team and specialists. In 1980, the neonatal ECMO project moved to the University of Michigan. By the end of 1986, 715 newborn cases had been treated in 18 centers with excellent survival results reported from each center. The Michigan group carried out a prospective randomized study in newborn infants between 1982 and 1984, using a statistical technique called randomized play-the-winner, in which assignment to one treatment or the other is randomized but influenced by all previous patients in the study. Statistical significance is reached when there is a significantly larger group of patients in one arm of the study compared with the other (1). O'Rouke et al. carried out a prospective randomized study comparing ECMO and conventional medical therapy in neonates with persistent pulmonary hypertension of the newborn between 1982 and 1983 (2). They proved that the results with ECMO were better than conventional therapy. 
ECMO became standard care for severe neonatal respiratory failure in 1986-87. In 1988, venovenous bypass using a double lumen catheter became available with excellent outcome (3). The current technique of ECMO includes venoarterial access via the right internal jugular vein and right carotid artery, heparin titration based upon whole blood activated clotting times (ACT), and "lung rest" at low ventilator settings (4). The extracorporeal circuit consists of a collapsible bladder in the venous line (providing control of a roller pump) and a solid silicone rubber membrane oxygenator (Avecor, Inc. Minneapolis, MN). Blood is circulated through a heat exchanger and then returned to the patient. Sweep gas flow to the oxygenator typically consists of a mixture of $100 \%$ oxygen, carbogen $(95 \%$ oxygen and $5 \%$ carbon dioxide) to maintain $\mathrm{PaCO}_{2}$ between 30 and $40 \mathrm{~mm} \mathrm{Hg}$. Anticoagulation is achieved by constant heparin infusion, maintaining the ACT between 180 and $200 \mathrm{~s}$. Platelet counts are maintained above $100,000 / \mathrm{mm}^{3}$. The hematocrit values are kept above $40 \%$. Initial bypass flow is about $80-100 \mathrm{ml} /$ $\mathrm{kg} / \mathrm{min}$ in the venoarterial bypass mode and $100-120$ $\mathrm{ml} / \mathrm{kg} / \mathrm{min}$ in the venovenous mode. Patients are weaned according to $\mathrm{SVO}_{2}$ and $\mathrm{PaO}_{2}$ values. On initiation of bypass, ventilator settings are decreased to an inspired oxygen concentration of $30 \%$, peak airway pressure $<30 \mathrm{~cm}$ of $\mathrm{H}_{2} \mathrm{O}$, PEEP usually maintained at $5 \mathrm{~cm}$ of $\mathrm{H}_{2} \mathrm{O}$, and a respiratory rate of 10 beats/min.

The active groups formed a study group in 1989 called the Extracorporeal Life Support Organization (ELSO). ELSO maintains the registry, conducts courses, holds an annual meeting to share experience, and represents the membership to the community. Schumacher et al. reported a cost effectiveness study demonstrating that the early use of ECMO does not increase hospital cost or utilization and suggests a lower morbidity rate (5). The application of ECMO is now being extended to premature and low birth weight infants (6). A follow-up study reported that $80 \%$ of survivors were healthy children. The remaining $20 \%$ have some degree of pulmonary or neurologic impairment. Death or disability is caused by perinatal neurologic injury or pulmonary hypoplasia (7). In 1994, there were nearly 100 ECMO centers throughout the world. Over 9,000 newborn infants have been treated with ECMO with an $81 \%$ overall survival rate (Table 1) (8). Bleeding was the most frequent complication. ECMO is now standard treatment for severe neonatal respiratory failure. The availability of ECMO has made the evaluation of other innovative methods of treatment, such as late elective repair
TABLE 1. Percent survival by primary diagnosis for neonatal ECMO

\begin{tabular}{lll}
\hline \multicolumn{1}{c}{$\begin{array}{c}\text { Primary } \\
\text { diagnosis }\end{array}$} & $\begin{array}{c}\text { University of } \\
\text { Michigan }^{a} \\
(\mathrm{n}=470)\end{array}$ & $\begin{array}{c}\text { International } \\
\text { registry } \\
(\mathrm{n}=9,258)\end{array}$ \\
\hline MAS & $97 \%(165 / 170)$ & $93 \%(3,173 / 3,395)$ \\
RDS/HMD & $\mathbf{8 8 \% ( 8 0 / 9 1 )}$ & $84 \%(879 / 1,051)$ \\
Pneumonia/sepsis & $83 \%(65 / 78)$ & $76 \%(1,091 / 1,431)$ \\
CDH & $66 \%(45 / 68)$ & $58 \%(1,057 / 1,808)$ \\
PPHN/PFC & $92 \%(35 / 38)$ & $83 \%(1,008 / 1,209)$ \\
Air leak syndrome & $0 \%(0 / 1)$ & $72 \%(31 / 43)$ \\
Other & $75 \%(18 / 24)$ & $78 \%(250 / 321)$ \\
Overall & $87 \%(408 / 470)$ & $81 \%(7,489 / 9,258)$
\end{tabular}

MAS, meconium aspiration syndrome; RDS, respiratory distress syndrome; HMD, hyaline membrane disease; $C D H$, congenital diaphragmatic hernia; PPHN, persistent pulmonary hypertension of the newborn; PFC, persistent fetal circulation.

${ }^{a}$ Includes initial 45 cases treated at the University of California-Irvine. Data from the ECMO registry report of the ELSO as of July 1994.

of diaphragmatic hernia, and new pulmonary vasodilators, such as nitric oxide (9) possible.

\section{PEDIATRIC AND ADULT ECMO}

An NIH-sponsored study of ECMO in adult patients was completed in 1979 and reported (10). Although there were many problems with this study, this was the first attempt at a prospective randomized study of the ECLS technique in which the end point was death. Some centers had no prior experience before their first study patient. Bleeding complications were major with average blood loss exceeding $2 \mathrm{~L} /$ day. Although the purpose of ECMO is lung rest, many of the patients remained on high ventilator settings under the venoarterial bypass mode. The study was planned for 300 patients, but it was terminated after 92 patients were entered because the survival in both groups was less than $10 \%$. Autopsy revealed that extensive and irreversible pulmonary fibrosis was uniformly formed, indicating that the major problem was underlying parenchymal lung disease. As the result of this study, clinical research on ECMO in adult patients essentially stopped in the United States in 1979. Gattinoni and his colleagues in Milan started using a new method for extracorporeal life support with the following hypothesis. First, the purpose of ventilation is to excrete carbon dioxide. Oxygenation can be achieved by inflation and airway oxygenation alone. Second, progressive lung injury in acute respiratory distress syndrome (ARDS) is caused in part by ventilator-induced high pressure or overdistension injury of the most normal alveoli. Third, if the emphasis should be on carbon dioxide removal to eliminate the need for high pressure ven- 
tilation, this could be accomplished with venovenous access using relatively low blood flow and a large membrane lung surface area. Fourth, this system would allow for normal pulmonary blood flow, even if the lung is severely injured with large amounts of transpulmonary shunting. They used these principles in venovenous extracorporeal gas exchange with low-frequency positive pressure ventilation in a variety of adult patients selected by the same criteria used for the NIH ECMO study. They reported their study with $49 \%$ survival in 1986 (11). These results have been corroborated in many European centers, and similar results were reported by the Kumamoto group in Japan.

Based on these reports and our experience with neonatal ECMO, our institute began to reevaluate ECMO in adult patients with cardiopulmonary failure in 1988. The ECMO technique for adult patients is the same as neonatal ECMO, including the venovenous and venoarterial bypass mode with lung rest. Selection criteria for respiratory failure in adults with $90 \%$ or greater mortality risk includes transpulmonary shunt greater than $30 \%$, static compliance lower than $0.5 \mathrm{ml} / \mathrm{cm}$ of $\mathrm{H}_{2} \mathrm{O} / \mathrm{kg}$, and a diffusely abnormal chest roentgenogram in four quadrants despite optimal conventional therapy (12). Bleeding was the most frequent complication. Indicators of irreversibility of lung injury in these patients were elevated pulmonary artery pressures (75\% or greater of systemic pressure), decreased aeration and lung compliance, and a diminution of transpulmonary gas exchange. Patients with more than 5 pre-ECMO ventilation days had a significantly higher mortality risk compared with those ventilated for less than 5 days. The elevated pulmonary artery pressure/systemic pressure ratio, transforming growth factor $\beta$ (TGF- $\beta$ ) activity in the Broncho alveolar lovage fluid (BALF), and measurement of oxygen transfer across the native lung during ECMO may be good early predictors for the

TABLE 2. Percent survival by primary diagnosis for pediatric ECMO

\begin{tabular}{lcl}
\hline \multicolumn{1}{c}{$\begin{array}{c}\text { Primary } \\
\text { diagnosis }\end{array}$} & $\begin{array}{c}\text { University of } \\
\text { Michigan } \\
(\mathrm{n}=62)\end{array}$ & $\begin{array}{c}\text { International } \\
\text { registry } \\
(\mathrm{n}=754)\end{array}$ \\
\hline Bacterial pneumonia & $100 \%(3 / 3)$ & $44 \%(28 / 63)$ \\
Viral pneumonia & $73 \%(16 / 22)$ & $53 \%(120 / 225)$ \\
Intrapulmonary hemorrhage & $100 \%(1 / 1)$ & $64 \%(7 / 11)$ \\
Aspiration & $67 \%(4 / 6)$ & $61 \%(45 / 74)$ \\
Pneumocystis & $0 \%(0 / 0)$ & $42 \%(5 / 12)$ \\
ARDS & $0 \%(0 / 1)$ & $32 \%(6 / 19)$ \\
Other & $66 \%(19 / 29)$ & $46 \%(162 / 350)$ \\
Overall & $66 \%(41 / 62)$ & $49 \%(373 / 754)$ \\
\hline
\end{tabular}

ARDS, adult respiratory distress syndrome. Data from ECMO registry report of the ELSO.
TABLE 3. Percent survival by primary diagnosis for adult ECMO

\begin{tabular}{ll}
\hline Primary diagnosis & $\begin{array}{c}\text { University of Michigan } \\
(\mathrm{n}=48)\end{array}$ \\
\hline Bacterial pneumonia & $14 \%(1 / 7)$ \\
Viral pneumonia & $88 \%(7 / 8)$ \\
Aspiration & $67 \%(2 / 3)$ \\
ARDS & $70 \%(16 / 23)$ \\
Other & $57 \%(4 / 7)$ \\
Overall & $63 \%(30 / 48)$ \\
\hline
\end{tabular}

ARDS, adult respiratory distress syndrome. Data from ECMO registry report of the ELSO.

reversibility of lung injury. As of July 1994,48 patients with severe respiratory failure have been treated with ECMO with 30 survivors $(63 \%)$ at the University of Michigan (Table 2) (8). The difference in the results of modern ECMO and those of the 1970s, when the NIH-ECMO study was performed, may in part be due to better case selection, venovenous perfusion, and improvement in the technology of long-term perfusion (12). Advances in critical care techniques today may improve the survival from respiratory failure.

For older children (between 1 month and 18 years of age) who have failed conventional mechanical ventilation, ECMO has also been proposed and utilized as a rescue therapy. As of July 1994, 754 pediatric cases have been treated with ECMO therapy with an overall survival rate of $49 \%$ (Table 3) (8). Our institute has experienced 62 cases with an overall survival rate of $66 \%(8)$. In the near future, routine use of heparin-coated equipment will reduce the complication associated with systemic heparinization and blood material interaction.

\section{CONCLUSION}

ECMO has become standard treatment for severe neonatal respiratory failure in our institute and worldwide. The application of ECMO is now being extended to premature and low birth weight infants as well as older children and adults. The outcome of ECMO for adult and pediatric patients in our institute showed that it was a reasonable therapy for patients with severe respiratory failure who failed to recover with conventional medical therapy. Technical advances will lead to a better outcome with much easier and safer use of ECMO in the future.

Acknowledgment: Supported in part by grants from the National Institute of Health and the William Randolph Hearst Foundation. 


\section{REFERENCES}

1. Bartlett RH, Roloff DW, Cornell RG, Andrews AF, Dillon PW, Zwishenberger JB. Extracorporeal circulation in neonatal respiratory failure: A prospective randomized study. Pediatrics 1985;76:479-87.

2. O'Rouke PP, Crone RK, Vacanti JP, Ware JH, Lilehei CW, Parad RB, Epstein MF. Extracorporeal membrane oxygenation and conventional medical therapy in neonates with persistent pulmonary hypertension of the newborn: A prospective randomized study. Pediatrics 1989;84:957-63.

3. Anderson HL, Snedcor SM, Otsu T, Bartlett RH. Multicenter comparison of conventional venoarterial access versus venovenous double-lumen catheter access in newborn infants undergoing extracorporeal membrane oxygenation. $J$ Pediatr Surg 1991;28:530-4.

5. Schumacher RE, Roloff DW, Chapman RA, Snedecor S, Bartlett RH. Extracorporeal membrane oxygenation in term newborns. ASAIO J 1993;39:873-9.

6. Bui KC, LaClair P, Vanderkerhove J, Bartlett RH. ECMO in premature infants: Review of factors associated with mortality. ASAIO Trans 1991;37:54-9.

7. Schumacher RE, Roloff DW, Chapman R, Bartlett RH. Follow-up of infants treated with extracorporeal membrane ox- ygenation for newborn respiratory failure. Pediatrics 1991; 87:451-7.

8. ECMO registry report of the extracorporeal life support organization. July 1994.

9. Shanley CJ, Hirschl RB, Schumacher RE, Overbeck MC, Delosh TN, Chapman RA, Coran AG, Bartlett RH. Extracorporeal life support for neonatal respiratory failure: A 20year experience. Ann Surg 1994;220:269-82.

10. Zapol WM, Snider MT, Hill JD, Fallat RJ, Bartlett RH, Edmunds LH, Morris AH, Peirce EC, Thomas AN, Proctor HJ, Drinker PA, Pratt PC, Bagniewski A, Miller RG. Extracorporeal membrane oxygenation in severe acute respiratory failure: A randomized prospective study. JAMA 1979; 242:2193-6.

11. Gattinoni L, Pesenti A, Masheroni D, Marcolin R, Fumagalli R, Rossi F, Iapichino G, Romagnoli G, Uziel L, Agostoni A, Kolobow T, Damia G. Low-frequency positive-pressure ventilation with extracorporeal $\mathrm{CO}_{2}$ removal in severe acute respiratory failure. JAMA 1986;256:881-6.

12. Anderson H, Steimle C, Shapiro M, Delius R, Chapman R, Hirschl R, Bartlett RH. Extracorporeal life support for adult cardiopulmonary failure. Surgery 1993;114:161-73. 